\title{
Heartbeat: Heart disease and COVID-19
}

During the COVID-19 pandemic it has become evident that the interaction between COVID-19 infection and cardiovascular disease goes both ways: patients with underlying cardiovascular disease (CVD) are at higher risk of adverse outcomes if infected; conversely, regardless of the presence of absence of underlying cardiovascular disease, acute myocardial injury is common in patients with COVID-19 infection. In this issue of Heart Wei and colleagues ${ }^{1}$ report that in a prospective study of 101 cases of COVID-19 in Sichuan, China, acute myocardial injury was present in $15.8 \%$ of patients, with an elevation in high-sensitivity troponin $\mathrm{T}$ (hs-TnT) more than five times normal in many patients. Clinical factors associated with an elevated hs-TnT were older age and pre-existing CVD. An elevated hs-TnT level was associated with a higher likelihood of mortality, admission to the intensive care unit, mechanical ventilation, and treatment with vasoactive agents. (table 1 )

In the accompanying editorial, Cheng and Leedy ${ }^{2}$ discuss the likely pathophysiology of myocardial injury in patient with COVID-19 infection including unmasking of underlying cardiovascular disease, coronary plaque rupture and cytokine release syndrome. They also emphasise the importance of identifying the underlying the mechanism of myocardial injury in each patient when possible suggesting that 'A better understanding of the drivers of myocardial injury on a case-by-case basis would provide guidance in decision-making and steer clinicians towards the right direction of treatment to maximise the chance of myocardial recovery.'

In a study from Wuhan, China, Zhang and colleagues ${ }^{3}$ looked at the severity and outcomes of COVID-19 infection in patients with underlying CVD. Of the 541 patients with COVID-19, CVD was present in $26.6 \%$ and was associated with a higher mortality $(22.2 \%)$ than in the overall study group $(9.8 \%)$ and a higher proportion of critically ill patients (27.8\% vs $8.8 \%)$. On multivariable logistic regression analysis, there was a lower likelihood of a full recovery and a higher risk of a critical

Correspondence to Professor Catherine M Otto, Division of Cardiology, University of Washington, Seattle, WA 98115, USA; cmotto@uw.edu

\begin{tabular}{lcccc} 
Table 1 & In-hospital clinical outcomes in 101 & cases of COVID-19 in Sichuan, China & \\
\hline & $\begin{array}{l}\text { Total } \\
(\mathrm{n}=101)\end{array}$ & $\begin{array}{l}\mathrm{hs}-\mathrm{TnT} \leq 14 \mathrm{pg} / \mathrm{mL} \\
(\mathrm{n}=85)\end{array}$ & $\begin{array}{l}\mathrm{hs}-\mathrm{TnT}>14 \mathrm{pg} / \mathrm{mL} \\
(\mathrm{n}=16)\end{array}$ & P value \\
\hline Death, $\mathrm{n}(\%)$ & $3(3.0)$ & 0 & $3(18.8)$ & $<0.001$ \\
\hline Severe case, $\mathrm{n}(\%)$ & $37(36.6)$ & $25(29.4)$ & $12(75)$ & 0.001 \\
Admission to ICU, $\mathrm{n}(\%)$ & $31(30.7)$ & $21(24.7)$ & $10(62.5)$ & 0.003 \\
\hline Mechanical ventilation, $\mathrm{n}(\%)$ & $11(10.9)$ & $4(4.7)$ & $7(43.5)$ & $<0.001$ \\
Vasoactive agents, $\mathrm{n}(\%)$ & $5(5.0)$ & 0 & $5(31.2)$ & $<0.001$ \\
ICU duration, mean (SD) & $3.26(6.16)$ & $2.86(5.56)$ & $5.38(8.61)$ & 0.135 \\
\hline
\end{tabular}

ICU, intensive care unit. disease course in those with underlying CVD (OR: 2.735 (95\% CI 1.495 to 5.003).

Chaterjee and Cheng ${ }^{4}$ propose that the association between underlying CVD and risk of adverse outcomes with COVID-19 infection should inform our approach to care of our patients with CVD during the COVID-19 pandemic. (figure 1) Further, they put forth the idea that: 'More broadly, CVD on the effectiveness of clinical therapies for COVID-19, we would advocate stratifying analyses of investigational COVID-19 therapies by CVD status.'

The association between CVD, myocardial injury and adverse outcomes in patients with COVID-19 infection was explored further in a systematic review and metaanalysis by Li and colleagues ${ }^{5}$ that included 10 studies with a total of over 3000 patients with COVID-19 infection. The OR for in-hospital mortality was almost five times higher for patients with underlying CVD, 3 to 4 times higher for those with hypertension, and 20 times higher for those with acute cardiac injury. (figure 2) given the potential effect modification of
Newby and Rahimi ${ }^{6}$ comment that a 'possible explanation for these associations is that the presence of cardiovascular disease is not only an indicator of older age but a marker of other non-cardiovascular comorbidities.' 'Nonetheless, there are a number of reasons to indicate that cardiovascular disease is mechanistically related to adverse outcome of COVID19.' 'Overall, the systematic review by $\mathrm{Li}$ and colleagues ${ }^{5}$ has confirmed that, in patients with COVID-19, there are strong associations between mortality and cardiovascular disease or cardiac injury. These observed associations lend major support to the hypothesis of direct and indirect cardiovascular consequences as being a contributor to or a mediator of the increased mortality seen in patients with COVID-19.'

Also in this issue of Heart, three review articles address various aspects of COVID-19 infection and heart disease. Imazio and colleagues ${ }^{7}$ explore the potential mechanisms of myocardial injury in patients with COVID-19 infection. (figure 3)

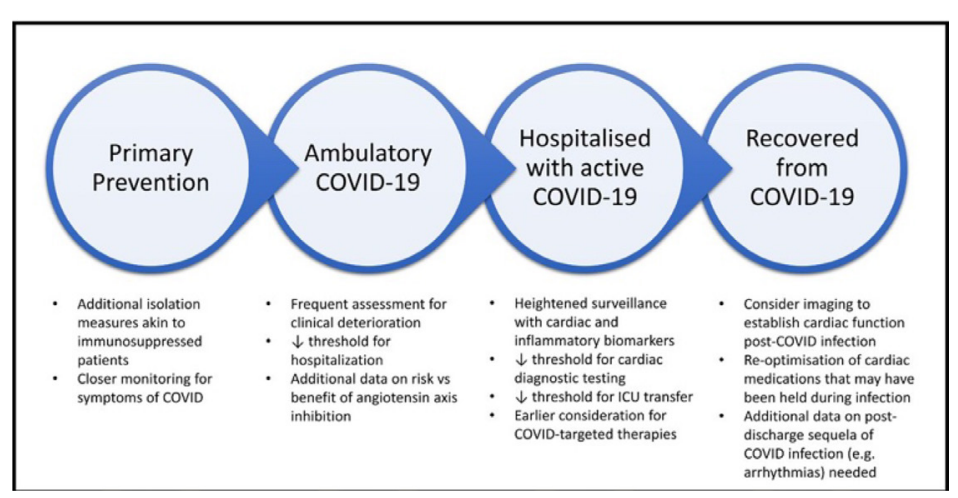

Figure 1 Caring for the patient with CVD during the COVID-19 pandemic. CVD, cardiovascular disease; ICU, intensive care unit. 


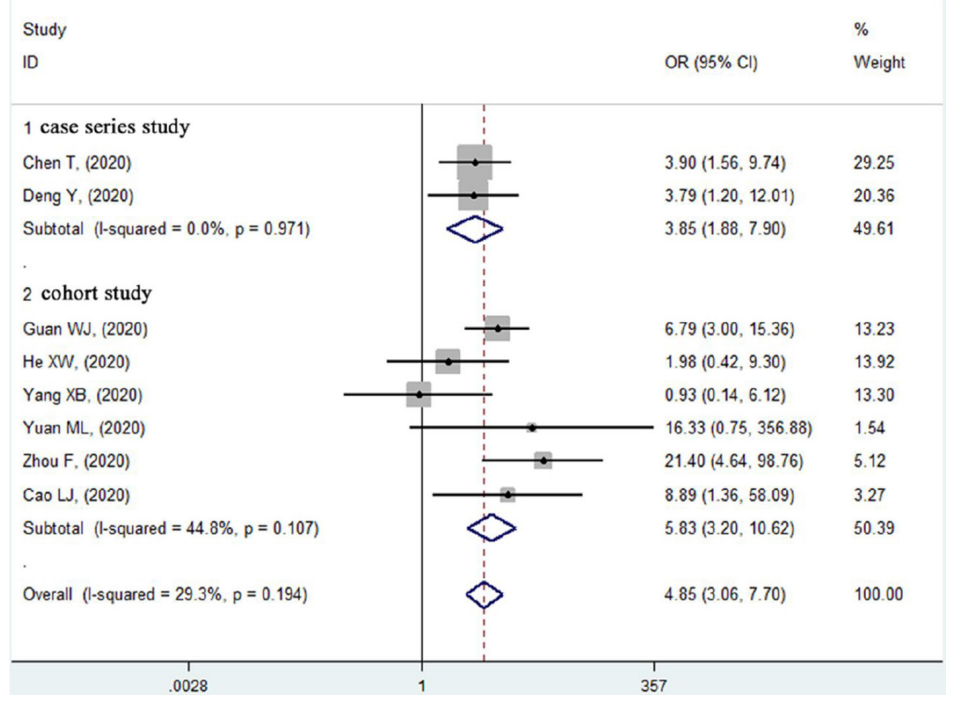

Figure 2 Forest plot of the relationship between pre-existing cardiovascular disease and inhospital mortality risk in patients with COVID-19.

Rowland and Kunadian ${ }^{8}$ discuss the challenges we currently face in management of older patients with an acute coronary syndrome during the COVID-19 pandemic. The Education in Heart article by Khialani and MacCarthy ${ }^{9}$ outlines an approach to ensuring continued access to transcatheter aortic valve implantation during the COIVD-19 pandemic, balancing the risks of infection and use of limited supplies of personal protective equipment against the risk of adverse outcomes with in symptomatic adults with severe aortic stenosis who do not undergo prompt intervention.
Other articles recently published in print or online first in Heart related to COVID-19 infection include a review article on cardiovascular manifestations and treatment considerations, ${ }^{10}$ a short commentary on the effectiveness of masks based on previous experience with air pollution ${ }^{11}$ and a discussion of management of patients with adult congenital heart disease ${ }^{12}$ during the COVID-19 pandemic.

Funding The authors have not declared a specific grant for this research from any funding agency in the public, commercial or not-for-profit sectors.
Competing interests None declared.

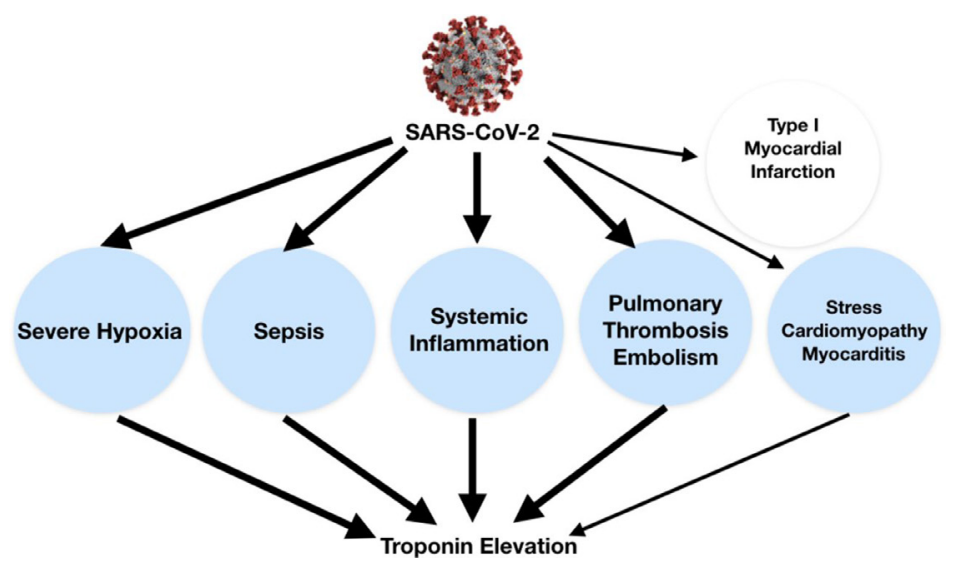

Figure 3 Troponin elevation in the setting of COVID-19 can be related to non-ischaemic myocardial injury (blue circles) by different possible mechanisms (eg, severe hypoxia, sepsis, systemic inflammation, cytokine storm, pulmonary thrombosis and thromboembolism, stress cardiomyopathy, and myocarditis). Thicker lines underline the most common causes. SARS-CoV-2, severe acute respiratory syndrome coronavirus- 2 .

Patient and public involvement Patients and/or the public were not involved in the design, or conduct, or reporting, or dissemination plans of this research.

Patient consent for publication Not required.

Provenance and peer review Commissioned; internally peer reviewed.

This article is made freely available for use in accordance with BMJ's website terms and conditions for the duration of the covid-19 pandemic or until otherwise determined by BMJ. You may use, download and print the article for any lawful, non-commercial purpose (including text and data mining) provided that all copyright notices and trade marks are retained.

(c) Author(s) (or their employer(s)) 2020. No commercial re-use. See rights and permissions. Published by BMJ.

\section{(A) Check for updates}

To cite Otto CM. Heart 2020;106:1115-1116.

Heart 2020:106:1115-1116.

doi:10.1136/heartjnl-2020-317674

ORCID iD

Catherine M Otto http://orcid.org/0000-0002-05279392

\section{REFERENCES}

1 Wei J-F, Huang F-Y, Xiong T-Y, et al. Acute myocardial injury is common in patients with covid-19 and impairs their prognosis. Heart $2020 ; 106: 1154-9$.

2 Cheng R, Leedy D. COVID-19 and acute myocardial injury: the heart of the matter or an innocent bystander? Heart 2020;106:1122-4.

3 Zhang J, Lu S, Wang $X$, et al. Do underlying cardiovascular diseases have any impact on hospitalised patients with COVID-19? Heart 2020;106:1148-53.

4 Chatterjee NA, Cheng RK. Cardiovascular disease and COVID-19: implications for prevention, surveillance and treatment. Heart 2020;106:1119-21.

5 Li X, Guan B, Su T, et al. Impact of cardiovascular disease and cardiac injury on in-hospital mortality in patients with COVID-19: a systematic review and meta-analysis. Heart 2020;106:1142-7.

6 Newby DE, Rahimi K. Getting to the heart of the matter of COVID-19. Heart 2020;106:1117-8.

7 Imazio M, Klingel K, Kindermann I, et al. COVID-19 pandemic and troponin: indirect myocardial injury, myocardial inflammation or myocarditis? Heart 2020;106:1127-31.

8 Rowland B, Kunadian V. Challenges in the management of older patients with acute coronary syndromes in the COVID-19 pandemic. Heart 2020. doi:10.1136/heartjnl-2020-317011. [Epub ahead of print: 22 May 2020].

9 Khialani B, MacCarthy P. Transcatheter management of severe aortic stenosis during the COVID-19 pandemic. Heart 2020;106:1183-90.

10 Kang Y, Chen T, Mui D, et al. Cardiovascular manifestations and treatment considerations in covid-19. Heart 2020;106:1132-41.

11 Rajagopalan S, Huang S, Brook RD. Flattening the curve in COVID-19 using personalised protective equipment: lessons from air pollution. Heart 2020. doi:10.1136/heartjnl-2020-317104. [Epub ahead of print: 11 May 2020].

12 Radke RM, Frenzel T, Baumgartner H, et al. Adult congenital heart disease and the COVID-19 pandemic. Heart 2020. doi:10.1136/heartjnl-2020-317258. [Epub ahead of print: 10 Jun 2020]. 